\section{The Hippocampus, Memory, and Space}

\section{Larry R. Squire and Carolyn Backer Cave}

Veterans Affairs Medical Center and Department of Psychiatry, University of California, San Diego, CA 92161 U.S.A.

In the 1970s, there was considerable uncertainty about the function of the hippocampus. Study of the amnesic patient, H. M., who had sustained a bilateral medial temporal lobe resection, indicated that this region of the brain was important for memory functions (Scoville and Milner, 1957). However, the medial temporal lobe is a large region that includes not only the hippocampus, but also the amygdala and adjacent cortex. The relevance of the hippocampus itself to $\mathrm{H}$. M.'s memory impairment was uncertain. In addition, studies of rats and other animals with hippocampal lesions pointed in a number of directions other than memory, and there seemed to be little common ground in the work on different species (for reviews from this period, see Douglas, 1967; Kimble, 1968; Isaacson, 1974; Iversen, 1976).

Then, in 1978, four interesting things happened. First, Horel (1978) evaluated the available data and proposed that the important brain region for memory was not the hippocampus at all but temporal stem white matter, which lies adjacent to the hippocampus just above the lateral ventricle. This interpretation was subsequently ruled out by experiment, but the argument was cogently developed and demonstrated effectively that in 1978 the idea that the hippocampus is important for memory was not on firm ground. Second, it was reported that a large medial temporal lobe removal in the monkey, similar to the surgical lesion sustained by patient H. M., caused severe memory impairment (Mishkin, 1978). Although there was more to do before the impairment was fully understood (Mishkin et al., 1982; Squire and Zola-Morgan, 1983; Zola-Morgan and Squire, 1991), this publication was the first of a new era of work on the neuroanatomy of memory, and, in this sense, it signalled the successful establishment of an animal model of human amnesia in the nonhuman primate. The third event occurred in September 1978 , when patient $R$. B. became amnesic as the result of a postoperative ischemic event. After his death 5 years later, he was found to have selective bilateral damage to the CA1 region of the hippocampus. This case thereby provided compelling evidence that damage limited to the hippocampus could cause clinically significant memory impairment (ZolaMorgan et al., 1986). Finally, in the same year, O'Keefe and Nadel (1978) published their seminal book. Their view, which was influenced especially by work with rodents, was that the hippocampus is a cognitive map, a memory system that computes and stores information about allocentric (viewer-independent) space.

The function of the hippocampus is much better understood now than it was in 1978, and a case can be made that the findings from work with different species are in congruence. From a contemporary perspective, the spatial memory hypothesis advanced by O'Keefe and Nadel (1978) and reconsidered by Nadel (1991) was influential and far-sighted, but it provides an incomplete account of hippocampal function. Certainly. many findings are consistent with the idea that the hippocampus is involved in spatial memory. In rodents, damage to the hippocampus or related structures causes severe impairment in spatial memory tasks (for reviews, see Olton et al., 1979; Barnes, 1988). In addition, patients with hippocampal damage are impaired on spatial memory tasks (Milner, 1965; Warrington and Baddeley, 1974: Smith and Milner, 1981: Smith, 1988).

However, it is also the case that damage to the hippocampus produces memory impairment in nonspatial memory tasks. For example, in rodents. lesions of hippocampus or related structures impair odor discrimination learning ( $\mathrm{Ei}-$ chenbaum et al., 1988), the ability to time a short interval (Meck et al., 1984), and performance in configural discrimination tasks that require remembering unique combinations of stimuli (Sutherland et al., 1989: Rudy and Sutherland, 1989). In monkeys, visual object recognition and the learning of simple visual object discriminations are impaired following damage to the hippocampal formation (Squire and Zola-Morgan, 1983: Zola-Morgan et al., 1989). In humans, the impairment also extends beyond spatial material and includes impaired memory for autobiographical events, verbal material, time, faces, tactual sensations, music, and odors. An earlier comment on the cognitive mapping hypothesis, which is applicable today, stated: "It seems doubtful that this memory defect can be considered spatial in any interesting way, since the defect includes memory loss for material that is not spatial in the ordinary sense" (Squire, 1979, p. 514).

Although the hippocampus is clearly not involved in spatial memory exclusively, it is still possible to suppose that spatial functions are more important, or more fundamental, operations of the hippocampus than other, nonspatial functions. For example, it has remained possible that the hippocampus plays a disproportionately large role in spatial memory compared to other kinds of memory. In this view, hippocampal damage might impair both spatial and nonspatial memory, but spatial memory would be more severely impaired. A second possibility is that the hippocampus is needed to carry out certain kinds of (allocentric) spatial computations, even within immediate memory. Immediate memory, as measured by digit span, is intact in severely amnesic patients, including patients with hippocampal damage, but immediate memory has not been carefully evaluated using other kinds of material. Is it possible that patients with hippocampal damage have difficulty performing spatial computations within immediate memory?

Recently, it has been possible to test both of these ideas in amnesic patients with confirmed damage to the hippocampus. To test the idea that spatial memory might be disproportionally impaired in patients with hippocampal damage, subjects studied an array of 16 toys (cf. Smith and Milner, 1981) and were then given tests of object name recall, object name recognition, and object location (Cave and Squire, 1991). By testing control subjects after a long retention delay 
(3-5 weeks), it was possible to match their object memory performance to that of the patients (who were tested after a delay of 5 minutes). At this same delay, the spatial memory performance of the control subjects also matched the spatial memory performance of the patients. Thus, the impairment in location memory exhibited by the amnesic patients was proportional to the impairment in object memory. These findings suggest that spatial and nonspatial memory are equivalently impaired following hippocampal damage.

Recent comparisons of spatial location memory and object memory in monkeys with hippocampal lesions did find a more severe impairment in object-place association learning than in visual object memory (Mishkin, 1978; Parkinson et al., 1988). However, it is not clear in this case that the two tasks differ only in the dimension of interest, that is, that the only relevant difference is that one task is spatial and the other is not. For example, the object-place task required that the location of an object be recalled, while the visual object task required that an object be recognized as familiar. Recall is more difficult than recognition, and in humans recall tasks are much more sensitive to the effects of hippocampal damage than recognition memory tasks.

To test the possibility that patients with hippocampal damage might fail spatial tasks within immediate memory, amnesic patients and control subjects performed three different tasks requiring either retention or mental manipulation of spatial information within the span of immediate memory (Cave and Squire, unpublished observations). All three tasks were sufficiently difficult that errors were common, even at the shortest study-test intervals $(0-1$ seconds). Yet. the patients performed entirely normally at the short delays. They were able to remember the location of a dot on a line, they could remember the relative orientations of two lines that formed an angle, and they could perform mental mirror reversals of visually presented patterns. These findings suggest that the hippocampus is not functioning to carry out spatial computations in immediate memory.

The cognitive mapping hypothesis, as originally formulated (O'Keefe and Nadel, 1978) and as summarized by Nadel (1991), provides too narrow a view of hippocampal function. Spatial memory tasks are simply a good example of a broader category of memory tasks that require the hippocampus. The hippocampus is essential for the acquisition of information about combinations, conjunctions, and relationships among stimuli and stimulus features (Sutherland and Rudy, 1989; Eichenbaum et al., 1989; Squire et al., 1989). Representations established with the participation of the hippocampus have particular characteristics (e.g., they are often formed rapidly, are flexible and accessible to multiple response systems, and are accessible to conscious recollection). Learning that occurs without the participation of the hippocampus is often gradual, is relatively inflexible, and is expressed through performance without access to conscious recollection.

Although the hippocampus is important in spatial memory, it plays no special role in this regard. The cognitive mapping hypothesis could be made sufficiently general to encompass the findings discussed here, but it would then be difficult to distinguish it from other views that describe the function of the hippocampus in broader, more abstract terms (e.g., de- clarative, configural, or relational). Whatever terms are used to describe the kind of memory that depends on the hippocampus, experimental work since 1978 has moved gradually to the conclusion that spatial (allocentric) memory is an exemplar of a more abstract category. Findings from rats, monkeys, and humans now appear to be in good correspondence on this point.

\section{ACKNOWLEDGMENTS}

Supported by the Medical Research Service of the Department of Veterans Affairs; the National Institute of Mental Health (NIMH) grant $\mathrm{MH} 24600$; a postdoctoral fellowship to C. B. Cave, MH09913; the Office of Naval Research; the McKnight Foundation; and a Bioscience Grant for International Joint Research from NEDO, Japan.

\section{References}

Barnes, C. A. (1988) Spatial learning and memory processes: The search for their neurobiological mechanisms in the rat. TINS 11:163-169.

Cave, C. B., and L. R. Squire (1991) Equivalent impairment of spatial and nonspatial memory following damage to the human hippocampus. Hippocampus I,

Douglas. R. J. (1967) The hippocampus and behavior. Psych. Bull. $67: 416-442$.

Eichenbaum, H., A. Fagan, P. Mathews, and N. Cohen (1988) Hippocampal system dysfunction and odor discrimination learning in rats: Impairment or facilitation depending on representational demands. Behav. Neurosci. 102:231-339.

Eichenbaum. H., P. Mathews, and N. Cohen (1989) Further studies of hippocampal representation during odor discrimination learning. Behav. Neurosci. 103:1207-1216.

Horel. J. A. (1978) The neuroanatomy of amnesia: A critique of the hippocampal memory hypothesis. Brain 101:403-445.

Isaacson, R. L. (1974) The Limbic System. Plenum Press, New York, NY

Iversen, S. D. (1976) Do hippocampal lesions produce amnesia in animals? Int. Rev. Neurobiol. 19:1-49.

Kimble, D. P. (1968) Hippocampus and internal inhibition. Psychol. Bull. 70:285-295

Meck, W. H., R. M. Church. and D. S. OIton (1984) Hippocampus, time and memory. Behav. Neurosci. 98:3-22.

Milner, B. (1965) Visually-guided maze learning in man: Effects of bilateral hippocampal, bilateral frontal, and unilateral cerebral lesions. Neuropsychologia 3:317-338.

Mishkin, M. (1978) Memory in monkeys severely impaired by combined but not by separate removal of the amygdala and the hippocampus. Nature 273:29-298.

Mishkin, M., B. J. Spiegler, R. C. Saunders, and B. J. Malamut (1982) An animal model of global amnesia. In Toward a Treatment of Alzheimer's Disease, S. Corkin, K. L. Davis, J. H. Browdon. E. J. Usdin and R. J. Wurtman, eds., pp. 235-247, Raven Press, New York, NY.

Nadel, L. (1991) The hippocampus and space revisited. Hippocampus $1: 221-229$.

O'Keefe, J., and L. Nadel (1978) The Hippocampus as a Cognitive Map. Oxford University Press, London.

Olton, D. S., J. T. Becker, and G. E. Handelman (1979) Hippocampus, space, and memory. Behav. Brain Sci. 2:313-365.

Parkinson, J. K., E. A. Murray, and M. Mishkin (1988) A selective mnemonic role for the hippocampus in monkeys: Memory for the location of objects. J. Neurosci. 8:4159-4167. 
Rudy, J. W., and R. J. Sutherland (1989) The hippocampal formation is necessary for rats to learn and remember configural discriminations. Behav. Brain Res. 34:97-109.

Scoville, W. B., and B. Milner (1957) Loss of recent memory after bilateral hippocampal lesions. J. Neurol. Neurosurg. Psychiatry 20:11-21.

Smith, M. L. (1988) Recall of spatial location by the amnesic patient H. M. Brain Cogn. 7:178-183.

Smith, M. L., and B. Milner (1981) The role of the right hippocampus in the recall of spatial location. Neuropsychologia 19:781-793.

Squire, L. R. (1979) The hippocampus, space and human amnesia. Behav. Brain Sci. 2:514-515.

Squire, L. R., and S. Zola-Morgan (1983) The neurology of memory: The case for correspondence between the findings for human and nonhuman primate. In Physiological Basis of Memory, 2nd ed. J. A. Deutsch, ed., pp. 199-268. Academic Press, New York, NY.

Squire, L. R., A. P. Shimamura, and D. G. Amaral (1989) Memory and the hippocampus. In Neural Models of Plasticity, J. Byrne and W. Berry, eds., pp. 208-239 Academic Press, New York, NY.

Sutherland, R. J., and J. W. Rudy (1989) Configural association the- ory: The role of the hippocampal formation in learning, memory and amnesia. Psychobiology 17:129-144.

Sutherland, R. J., R. J. McDonald, C. R. Hill, and J. W. Rudy (1989) Damage to the hippocampal formation in rats selectively impairs the ability to learn cue relationships. Behav. Neural Biol. 52:331356.

Warrington. E. K., and A. D. Baddeley (1974) Amnesia and memory for visual location. Neuropsychologia 12:237-263.

Zola-Morgan, S. and L. R. Squire (1991) Neuropsychology of memory: Parallel findings in humans and nonhuman primates. In The Development and Neural Basis of High Cognitive Funtion, A. Diamond, ed., pp. 434-456. New York Academy of Sciences and MIT/Bradford Press, Cambridge, MA

Zola-Morgan, S. L. R. Squire, and D. G. Amaral (1986) Human amnesia and the medial temporal region: Enduring memory impairment following a bilateral lesion limited to the CA1 field of the hippocampus. J. Neurosci. 6:2950-2967.

Zola-Morgan, S.. L. R. Squire, and D. G. Amaral (1989) Lesions of the hippocampal formation but not lesions of the fornix or the mammillary nuclei produce long-lasting memory impairment in monkeys. J. Neurosci. 9:898-913. 